\title{
Riparian Vegetation Controls on Braided Stream Dynamics
}

\author{
Karen Gran*
}

Riparian vegetation can significantly influence the morphology of a river, affecting channel geometry and flow dynamics. In channels formed in non-cohesive material, vegetation is the main source of bank cohesion and could affect the overall behavior of the river, potentially constraining the flow from a multi-thread channel to a single-thread channel. To examine the effects of riparian vegetation on streams formed in non-cohesive material, we conducted a series of physical experiments at the St. Anthony Falls Laboratory. The first set of experiments examines the effects of varying densities of vegetation on braided stream dynamics. Water discharge, sediment discharge, and grain size were held constant. For each run, we allowed a braided system to develop, then halved the discharge, and seeded the flume with alfalfa (Medicago sativa). After ten to fourteen days of growth, we returned the discharge to its original value and continued the run for 30-36 hours. Our results show that the influence of vegetation on the overall river pattern varied systematically with the spatial density of plant stems. The vegetation reduced the number of active channels and increased bank stability, leading to lower lateral migration rates, narrower and deeper channels, and an increase in channel relief. All these effects increased with vegetation density. Vegetation also influenced flow dynamics, increasing the variance of flow direction in the vegetated runs, and increasing scour depths through strong downwelling where the flow collided with relatively resistant banks. This oblique bank collision provides a new mechanism for producing secondary flows. We found these bank collision driven secondary flows to be more important than the classical curvature-driven mechanism in the vegetated runs. The next set of experiments examines more closely how the channel pattern evolves through time, allowing for both channel migration and successive vegetation growth. In these on-going experiments, vegetation is reseeded following repeat high flow events, simulating the natural process of vegetation encroachment on the floodplain and channel.

University of Washington 